\title{
Dinámica de las relaciones amorosas en WhatsApp. Un análisis desde la semiótica ${ }^{7}$
}

\author{
Natalia Adelaida Gallo Carvajal \\ Estudiante de Comunicación Social \\ Universidad de Boyacá, Colombia \\ Correo electrónico: nagallo@uniboyaca.edu.co
}

\section{Lizeth Rocío Rojas Rojas}

Comunicadora Social Magíster en Semiótica Universidad de Boyacá, Colombia Correo electrónico: lizrojas@uniboyaca.edu.co
Recibido: 28/11/2019

Evaluado: $13 / 01 / 2020$

Aceptado: 03/02/2020

\section{Resumen}

Las redes sociales constituyen un aspecto fundamental en la vida de los jóvenes debido a que las relaciones interpersonales se establecen bajo parámetros distintos a épocas pasadas; por convención social se estereotipan y determinan las formas de sentir y pensar, abarcando áreas complejas como la de los sentimientos, donde el amor hoy por hoy es un término complicado de puntualizar. Por consiguiente, la presente comunicación determinó como finalidad analizar elementos lingüísticos y visuales que reúne la aplicación WhatsApp en un caso particular de interacción, desde una mirada teórica y metodológica propia de los estudios de la semiótica parisina. Dentro de los principales hallazgos se encuentra la pertinencia de las dinámicas de significación que, sujetas a componentes multimodales, influyen como una de las principales causas de las alteraciones comportamentales en una relación de pareja.

Palabras clave

Dinámica, comunicación, semiótica, WhatsApp.

7 Para citar este artículo: Gallo, N. y Rojas, L. (2021). Dinámica de las relaciones amorosas en WhatsApp. Un análisis desde la semiótica. Informes Psicológicos, 21(2), pp. 109-124http://dx.doi.org/10.18566/infpsic.v21n2a07 


\title{
Dynamics of love relationships on WhatsApp. An analysis from semiotics
}

\begin{abstract}
Social networks are a fundamental aspect in the lives of young people today, since interpersonal relationships are established under parameters different from those of the past. By social convention, the ways of feeling and thinking are stereotyped and determined, encompassing complex areas such as feelings, where love has become currently a difficult term to specify. Consequently, this study seeks to analyze linguistic and visual elements that the WhatsApp application brings together in a particular case of interaction, based on a theoretical and methodological perspective typical of studies of Parisian semiotics. Among the main findings is the relevance of the dynamics of significance that, when subject to multimodal components, may be one of the main causes of behavioral alterations in a couple relationship.
\end{abstract}

Keywords Dynamics, communication, semiotics, WhatsApp.

\section{Dinâmica das relações amorosas no WhatsApp. Uma análise da semiótica}

\section{Resumo}

As redes sociais constituem um aspecto fundamental na vida dos jovens, pois as relações interpessoais se estabelecem sob parâmetros diferentes dos do passado. Por convenção social, as formas de sentir e pensar são estereotipadas e determinadas, abrangendo áreas complexas como os sentimentos, onde amor na atualidade, é um termo difícil de pontualizar. Consequentemente, a presente comunicação teve como objetivo analisar os elementos linguísticos e visuais que a aplicação WhatsApp reúne num caso particular de interação, em uma perspectiva teórica e metodológica típica dos estudos da semiótica parisiense. Entre os principais achados está a relevância da dinâmica de significação que, sujeita a componentes multimodais, influencia como uma das principais causas de alterações comportamentais na relação de um casal. 


\section{ntroducción}

Con la llegada de la tecnología y el uso de aplicaciones móviles que facilitan la comunicación, se han planteado formas sencillas de mantener el contacto con otras personas; los jóvenes adoptan esta vía como alternativa para establecer y llevar sus relaciones amorosas, tomando como prioridad la interacción dada en el chat y, de igual forma, movilizando su emotividad según los textos escritos y las opciones visuales que se manejan en apps como Facebook, Instagram, WhatsApp, entre otras. Esta última, WhatsApp, es considerada -actualmente- como una de las redes más utilizadas a nivel mundial, principalmente por los jóvenes. Es una aplicación que se puede instalar en todos los smartphones o teléfonos inteligentes (Calero, 2014), convirtiéndose así en el sistema mundial de comunicación por excelencia.

Este éxito promueve inquietudes que se consideran relevantes toda vez que su practicidad hace posible sostener una conversación de forma más sencilla y eficaz entre los usuarios en relación con Facebook u otras aplicaciones que poseen características similares.

Entrando en materia, resulta imperioso tener presente que la base del escrito parte de las dinámicas comportamentales que se dan al interior de una relación de pareja, pero, en este caso, dicha dinámica es llevada a cabo no de manera cercana, directa, física, sino mediada a través de una app. De estas interacciones digitales emanan un sinfín de sensaciones que influyen en la cognición del ser humano y, por tanto, inciden claramente en su comportamiento de acuerdo con las convenciones establecidas que determinan cómo se debe llevar "correctamente" una relación de pareja. Cabe resaltar que tales consideraciones varían con respecto a la época y al uso hoy en día de los nuevos medios que han logrado penetrar en la construcción identitaria de los sujetos.

Las propiedades de WhatsApp en relación con las demás aplicaciones sobresalen por su particularidad de privacidad e inmediatez, siendo éstas: (i) la opción de activar o desactivar el doble check', (ii) la citación de los mensajes que facilita la comunicación con varias personas al mismo tiempo y en diferentes grupos, (iii) el dinamismo en la escritura con el uso de cursiva, negrilla y tachado, (iv) la conversión de videos a gifs, (v) la descarga de programas como PowerPoint, Microsoft Word, Microsoft Excel y PDF, y, por último, (vi) la inclusión de emojis o stickers a las fotos, entre otras.

Para el caso de la investigación, este gran dossier de propiedades invita a la pareja a tener un constante uso de la aplicación, sobre todo, de los componentes visuales como el emoji. Un emoji es una palabra japonesa que se usa para designar las imágenes o pictogramas que son empleados para expresar una idea, emoción o sentimiento en medios de comunicación digital. Desde la semiótica, estos formantes de tipo visual, lingüístico o

1 El doble check es un término utilizado para referirse a las palomitas en gris que aparecen debajo de cada mensaje. "Esto significa que el mensaje fue entregado al destinatario, pero de ninguna manera asegura que el mensaje haya sido leído, esto únicamente confirma que fue entregado" (Navarrete, 2013, párr. 7). 
kinésico se entienden como signos que, en palabras de Peirce (1931/1958), se definen como "un algo que está en lugar de otra cosa" (citado por Ruiz, 2005, p.177), es decir, herramientas de representación que motivan e intervienen en el accionar del individuo desde el ámbito psicológico y social.

Sobre el tema se destaca un considerable número de investigaciones realizadas desde la psicología, la sociología, la filosofía, y, por supuesto, la semiótica. Dentro de ellas, se encuentra "La pérdida del discurso amoroso en las nuevas tecnologías. Estudio de Caso de la Escuela Nacional Preparatoria del Colegio de Ciencias y Humanidades de la Universidad Nacional Autónoma de México", realizado por Óscar Rubelio Ramos Gómez (2013). En dicho documento se exploran las nuevas formas como los jóvenes se enamoran y demuestran este sentimiento a través del uso de redes sociales, a partir de los planteamientos expuestos por el semiólogo francés Roland Barthes en el texto "Fragmentos de un discurso amoroso".

De igual manera, las investigadoras Tania Rodríguez Salazar y Zeyda Rodríguez Morales en el 2016 plantean en el documento "El amor y las nuevas tecnologías: experiencias de comunicación y conflicto", cómo las nuevas tecnologías de la comunicación influyen en las relaciones amorosas de los jóvenes, en un caso particular de la ciudad de Guadalajara. Así mismo, el concepto de "amor líquido"2 se vuelve recurrente en los trabajos anteriores encontrando una exploración aún más exhaustiva en la investigación de María Cristina Giraldo Hurtado y Alexander Rodríguez Bustamante, denominada "La comunicación en las relaciones de pareja mediadas por la virtualidad en los tiempos de modernidad liquida" (2018). Al respecto, se tiene en cuenta la tesis de Bauman (2011) al mencionar que:

En una vida de continua emergencia, las relaciones virtuales superan fácilmente lo real. Aunque es ante todo el mundo offline el que impulsa a los jóvenes a estar constantemente en movimiento, tales presiones serían inútiles sin la capacidad electrónica de multiplicar los encuentros interpersonales, lo que les confiere un carácter fugaz, desechable y superficial. Las relaciones virtuales están provistas de las teclas suprimir $y$ spam que protegen de las pesadas consecuencias (sobre todo, la pérdida de tiempo) de la interacción en profundidad (p. 23).

En el mundo digital, las relaciones de pareja se valen de este tipo de herramientas para la construcción de un discurso más simbólico y, por ende, multifuncional a medida que la inmediatez del medio lo exige: las respuestas deben ser rápidas a fin de enterarse o mostrar interés, por ejemplo, en lo que está haciendo el otro, con quién y en dónde (Rodríguez \& Rodríguez, 2016). Estas actitudes comportamentales están precedidas por las emociones del sujeto, ya que se disponen de ellas según las circunstancias que provee el entorno y, de igual forma, proporcionan

2 Este es el título que le dio psicólogo polaco Zygmunt Bauman a uno de sus libros más vendidos. Amor líquido es un texto de largo aliento que trata sobre la debilidad de los vínculos humanos producida por la volatilidad de las sociedades humanas. 
sensaciones agradables o, de lo contrario, evitan situaciones que lleven al dolor u otro tipo de estados repulsivos. Ahora bien, el ser humano se ve inmerso en diferentes situaciones que lo movilizan a través de los sentimientos. El pensar y el actuar están reflejados por los tipos de discurso que pueden materializarse a través de textos de diversa índole, pero todos influenciados directamente por el sistema límbico ya que "(...) la construcción de sentimientos como instrumentos sociales fijan una emoción" (Montes, 2015, p. 4).

Pero, ¿de dónde proviene el sentir? Savan (1991), siguiendo la tríada sígnica propuesta por Charles Sander Peirce (1931/1958), distingue tres clases de sentimientos que nos dan luces sobre una posible respuesta: naturales, morales y lógicos. En relación con los naturales, se afirma que estos vienen inscritos biológicamente en el ser, un placer de saciarse cuando se siente hambre, por ejemplo, $\mathrm{y}$, como reafirma el autor, estos causan exclusivamente "la mera reacción". En segunda instancia, se habla de sentimientos morales que van ligados a juicios determinados por normas y aprendizajes, equivalentes a las emociones. La emoción es un concepto que se relaciona directamente con el odio, la ira y la tristeza, entre otros.

Con relación a lo anterior, se retoma la última categoría propuesta por Savan (1991) y que se relaciona directamente con la terceridad ${ }^{3}$ de Pierce (Restrepo, 1993) en donde se asume una implicación de la sensibilidad social del hombre como efecto de sentido para la sociedad. Las emociones se organizan y manifiestan de acuerdo al entorno y las características de la situación comunicativa en la que se encuentre el sujeto.

De manera que existen distintas concepciones e ideologías que intentan describir las dinámicas en las relaciones de pareja permeadas por las experiencias o el conocimiento que tiene sobre el tema cada individuo. Al respecto, Botero (2016) expone que "los adolescentes, son capaces de amar, pero necesitan de un sentimiento de entrega, madurez, y sacrificio, y compatibilidad con la otra persona" (párr. 2), allí, se evidencia la necesidad de interacción y afinidad con respecto a otro ser humano y se relaciona con el sentido que se le atribuye a la importancia de las relaciones interpersonales, factor fundamental de este análisis. Al respecto, Rubio-Romero y Perlado (2015) aseguran que:
Los usuarios de edades comprendidas entre los 16 a 34 años son los que consiguen mayores tasas de penetración en la aplicación. Aproximadamente siete de cada diez usuarios de estas generaciones dispone de Internet sobre el móvil, cuando la tasa en el conjunto de usuarios es del 59.6\%" (p. 76).

Es por ello que los datos señalan la relevancia de esta app para los jóvenes y el uso que le atribuyen en su cotidianidad.

3 La terceridad en palabras de Retrepo (1993), es "el modo de ser de la ley o del concepto. La idea de tercero se hace evidente en la representación, la generalidad, el infinito, la continuidad, la difusión, el crecimiento, la inteligencia. Es la categoría esencial del fenómeno que incluye y posibilita la concreción de las otras dos: cualidad y hecho. En la terceridad, como 'modo de ser', accedemos inteligiblemente a los fenómenos (...). Parafraseando a Pierce podemos decir que el pensamiento es el espejo -como representación del ser" (p.98). 
Al respecto Caballero (s.f.) citado por Piergiorgio (2014, párr. 4), señala:

Lo peor es cuando ves que el otro está en línea con el WhatsApp y no te contesta, porque significa que está hablando con otras personas. En el fondo, vamos de muy modernos y conectados, pero seguimos siendo muy convencionales en las relaciones.

Afirmación que expone las posibles inferencias y atribuciones a los significados que le conceden los jóvenes al famoso "visto" de la red social. Pero, a pesar de las tergiversadas interpretaciones, se ven atraídos por las alternativas gráficas y lo rápido que pueden "comunicarse" cotidianamente.

\section{Sobre el método de análisis}

El siguiente documento hace énfasis en teorías planteadas dentro del ámbito semiótico con el propósito de intentar explorar las dinámicas de interacción en pareja desde la percepción del joven, explorando los axiomas que intervienen en la producción de significados.

El procedimiento analítico comprende explorar los tres niveles de análisis semiótico propuesto por la Escuela Semiótica de París. Este modelo procede en tres niveles, que exploran las estructuras superficiales del objeto, seguidas de las estructuras narrativas o trasformaciones, para llegar a las estructuras fundamentales o sistema axiológico que de él se desprende. En otras palabras, se estarán dando respuestas a interrogantes como los siguientes: ¿Cómo está construido el objeto superficialmente?, ¿Qué narra? y ¿Cuáles son los valores que involucra?

En el primer nivel se describe la composición formal del emoji como imagen visual, iniciando por su apariencia y estructura, hasta esclarecer la razón del uso del color amarillo para determinarlo como símbolo universal, características necesarias que imbrican el proceder genérico del objeto, y, por ende, su pertinencia analítica. En el segundo nivel, se reconocen los esquemas de narración de la situación comunicativa, y las competencias de los sujetos participantes en relación con su forma de enviar e interpretar los mensajes, y, asimismo, los procesos de manipulación discursiva (Greimas \& Courtés, 1982).

Por último, se rescata el sistema axiológico como eje fundamental en la motivación de los individuos en el momento de accionar y cómo estos sentimientos constituyen un pilar importante en la interacción que se establece en las relaciones amorosas de los jóvenes en la actualidad, distinguidas por el uso excesivo de las redes, específicamente WhatsApp.

Con relación a la muestra recogida, se cuenta con cuatro pantallazos tomados de un chat a través de la aplicación WhatsApp de una pareja heterosexual joven entre los 20 y 23 años ${ }^{4}$, quienes son partícipes de una relación amorosa desde hace 9 meses aproximadamente,

4 Se debe agregar que es ineludible proteger la intimidad y privacidad de los participantes, por lo mismo, se mantendrá oculta su identidad en el análisis. 
cuyo medio de comunicación más frecuente es esta app. Para llegar a esta muestra se tuvo en cuenta la selección de (4) momentos de la conversación que, según el criterio de Jaques Fontanille (2001), cumplen con las características de lo que él llama en investigación semiótica, el mejor ejemplar ${ }^{5}$ entendido como aquella muestra que reúne las características (del todo) de la conversación seleccionada.

Para nombrar a los sujetos a lo largo del presente análisis, es necesario aclarar que se tipifican de la siguiente manera: aparece un sujeto con rasgos fenotípicos masculinos a quien se denominará personaje $1 \mathrm{y}$, de la misma manera, se clasificará al individuo con características femeninas como personaje 2 .

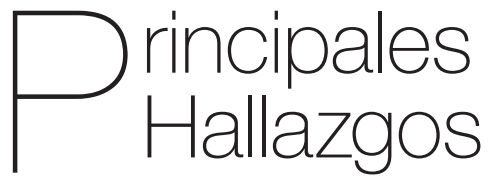

Como se mencionó, el análisis procede a través de capturas de pantallas a una de las conversaciones sostenidas por los dos sujetos fuente de esta exploración. Esta conversación muestra un estimado de 10 emoticones básicos, que son, en suma, los más antiguos que ofrece la app y mayormente lo más empleados por los personajes. Pero en concreto se estudiaron 4 emojis para abordar la primera fase del análisis.
El semiólogo Richard Danta (s.f., citado por Dutour, 2016) asegura que los emoticones como parte de una imagen "nos han acompañado y cumplido un papel socializador, comunicacional y expresivo tan importante como el leguaje" (párr. 4); es por esto que se emplean como signos para representar una palabra o expresión a modo de síntesis y, debido a su significado universal y su intención de hacer más ligera y rápida la conversación, se convierten en los símbolos más llamativos a la hora de comunicarse a través de la red. Su origen se remonta cuando el japonés Shinketaku Kurita diseñó las primeras caritas para los celulares en 1999 buscando una forma de comunicación más sencilla y eficaz a través de las pantallas (Dutour, 2016).

Como imagen visual, el emoji está compuesto en su mayoría por tres formas geométricas: un círculo principal en la parte superior centrada, dos más pequeños y una línea recta o curva (varía de acuerdo con la expresión y el significado del emoji). Debido al orden de su estructura, la figura se destaca por sus características icónicas y, gracias a su rol convencional, le posibilita tener el mismo significado en cualquier parte del mundo posicionándolo, así, como un símbolo.

El uso del círculo como forma, permite esa convención social debido a la relación directa con las características fenotípicas del ser humano, más explícitamente con el rostro. Dado que la función del emoticón se centra en la representación de las emociones humanas, en el aspecto

5 En palabras de Fontanille (2001), “(...) se puede organizar una categoría en torno a una ocurrencia particularmente representativa, a un ejemplar más visible o más fácilmente localizable que los otros y que posee él solo todas las propiedades que están parcialmente representadas en cada uno de los miembros de la categoría. (...) la formación de la categoría reposa entonces sobre la elección del mejor ejemplar posible" (p. 41). 
sincrético cabe resaltar las afirmaciones del psicólogo Paul Ekman (1972) quien aseguró que "(...) las expresiones faciales son un índice fidedigno de ciertas emociones básicas" (citado por Davis, 2010, p.71).

Para fundamentar su hipótesis, Ekman (1972) no sólo se centró en un acercamiento experimental, sino que trabajó en buscar un método científico que explicara mejor la transmisión de las emociones por medio de gestos fáciles. Decide reducir, entonces, a una fórmula canónica los miles de expresiones faciales que pueden realizar los músculos del rostro. Ésta se denomina FAST (Facial Affect Scoring Techinque), utilizando imágenes visuales (fotografías) en lugar de códigos lingüísticos. Se divide el rostro en tres áreas: la frente y las cejas, los ojos y el resto de la cara. Esta descomposición permite analizar la forma básica de cada órgano, como el arco de las cejas o la línea curva inferior de la boca que denota dos emociones (felicidad y tristeza), según la posición de ésta. Del mismo modo, las alteraciones en estos rasgos se dan de acuerdo a la sensación individual percibida. Ekman, en compañía de Oster (1979), toman como ejemplo el caso de la sorpresa, donde una boca abierta y ojos grandes y expresivos marcan su construcción significante.

No obstante, si se tienen en cuenta los parámetros señalados por la semiótica del cuerpo, más específicamente su morfología y en cómo esas significaciones de los gestos fáciles se generan e interpretan, José Enrique Finol (2015) plantea una división en tres niveles para el estudio de éste: bajo, medio y alto. Se explicará de forma breve únicamente el primero, denominado "nivel alto, de orografía facial", nivel en donde se diferencia la cara del rostro, argumentando que "la cara es física, natural: el rostro es una obra humana. El rostro es una construcción" (Vásquez, 1992, p. 45).

De igual forma, es necesario traer a colación otro aspecto indispensable en la parte figurativa del análisis. Basándose en el estudio de la imagen realizado por el Groupe $\mu$ en su texto "Tratado de Semiótica Visual” (1993), uno de los elementos que se plantea en la descripción de la imagen visual es el color, fundamentalmente en la escala cromática que maneja los atributos de tono, brillo y saturación. En este caso, resulta imprescindible esclarecer el por qué se utiliza el amarillo como color que identifica globalmente a los emojis.

Un artículo digital presentado por Fuentemayor (2007) declara que el origen del color de los emoticones es propuesto por la organización Consorcio Unicode, dedicada a establecer y facilitar el tratamiento informático, transmisión y visualización de textos de múltiples lenguajes y disciplinas técnicas. Esta Organización "Existe para que, en todo el mundo, cada carácter o signo esté clasificado" (párr.5). En cuanto al color, se afirma que, desde la creación del emoji, se buscó un color genérico creando sensación de neutralidad en cuanto a las razas. No obstante, se precisa que los tonos de piel están basados en el estándar dermatológico de la escala del Dr. Thomas Fitzpatrick en 1975. Dicha escala es utilizada para categorizar los tonos de la piel según la tolerancia a la luz solar, llamados fototipos cutáneos (Mubarak, 2013).

Dentro de este marco, Eva Heller (2004) refiere al amarillo como un color que comprende 115 tonos diferentes con 
diversos conceptos. A nivel general se reconoce por ser el color de la diversión, amabilidad y optimismo. También recalca cierta pureza al ser uno de los tres colores primarios y reflejar una de las tonalidades más claras de todos los colores. Sus miles de significaciones son contradictorias, ya que todo reside en el color con que se mezcle para que varíe la intención, así pues, ha de considerarse el uso del amarillo como signo de neutralidad, para concretar en un solo color las tipologías de pieles existentes con la intención de no discriminar a nadie.

Empero, cabe resaltar la opinión del lingüista argentino Ariel Torres (s.f.) quien sentencia: "(...) Gran parte de la comunicación humana es no verbal. Los emoticones añaden al texto de los mensajes esa noción, dado que allí no se espera

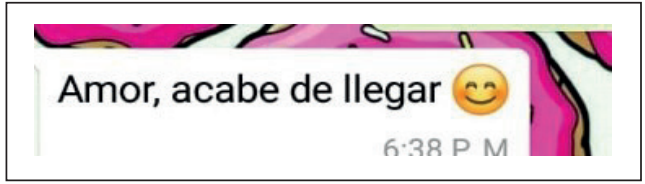

Figura 1.

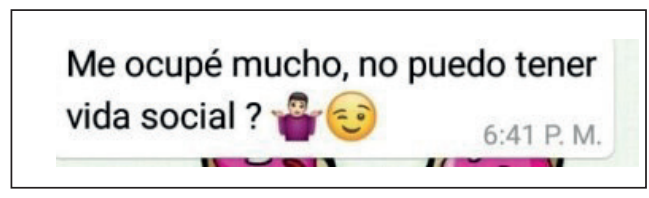

Figura 2.

Fuente: Capturas proporciondas para esta investigación

En este orden de ideas, es conveniente señalar un componente relevante del análisis lingüístico del objeto, concretamente el tiempo verbal en el que se desarrollan los hechos. Para ejemplificar se hará un breve parafraseo de la primera línea extraída del diálogo entablado hacer un largo y trabajoso ejercicio literario para describir emociones" (citado por Dutuor, 2016, párr.4). La opción de transformar los grafemas en imágenes visuales con tonalidades y formas llamativas a la vista humana para agregar dinamismo a las conversaciones es un punto clave para las nuevas formas de sentir que experimentan los jóvenes.

En relación con la exploración narrativa que hace parte de un segundo momento del análisis, los patrones repetitivos hallados en las siguientes muestras (figura 1, 1a, 2 y 2a) infieren la utilización recurrente de una figura retórica denominada sarcasmo, la cual hace referencia a la ironía según el contexto de la situación comunicativa que se presenta en dicho caso y, asimismo, la tergiversación del significado que se le adjudica al emoji.

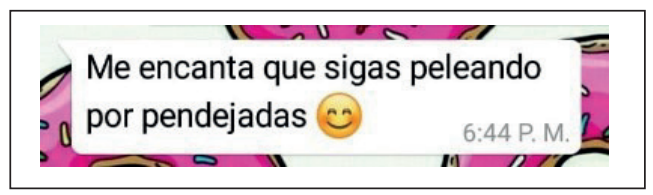

Figura 19.

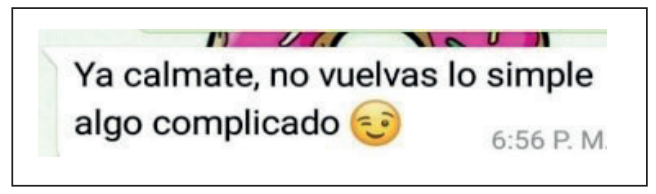

Figura 2a.

por los interlocutores: "Amor acabé de llegar": aquí se recalca la importancia del verbo acabé, como la acción que hace unos instantes ejecutó el personaje1; así mismo, se emplea para anunciar el momento en el que se da inicio a la conversación. 
Para determinar la interpretación de los mensajes y más específicamente la distorsión del concepto que se le adjudica tanto a los rasgos visuales como lingüísticos por parte de los personajes, es pertinente destacar que estos constituyen un factor primordial en el estudio temático narrativo y actancial, partiendo de las condiciones sujetas al individuo en la búsqueda de los objetos de valor, el rol de los personajes y los procesos de manipulación del ser humano.

Definir cuál es el objeto de valor que buscan constantemente los sujetos que sostienen una relación, va de la mano con la transformación que ellos sufren a lo largo de dicha búsqueda. En el caso de los intereses implícitos en los mensajes textuales con el uso de alegorías, como el sarcasmo y tono burlesco, puede resultar hiriente $u$ ofensivo, o como imágenes visuales llamativas (los emojis) que coadyuvan a la hermenéutica de los conceptos que se utilizan en la interlocución.

De otro lado, se manifiesta indirectamente ese estado de perturbación o enojo por parte del personaje 2 que evoluciona a lo largo de la conversación y, del mismo modo, se hace evidente el cambio en los patrones de la línea narrativa que llevan los mensajes enviados por el personaje 1. Esto corresponde a los grafemas y emojis que ellos reciben mutuamente y que causan efecto en los estados anímicos (Figura 3 , 3a y $\left.4,4 a^{6}\right)$.

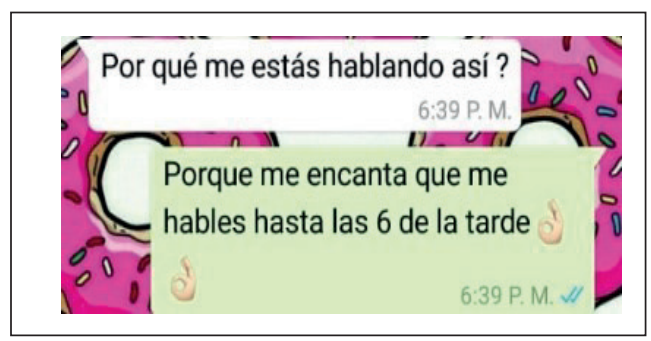

Figura 3a.

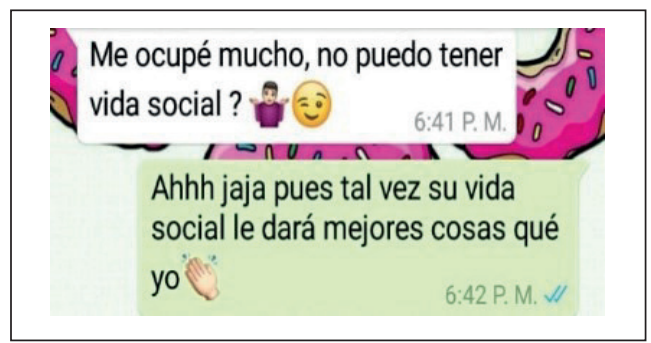

Figura 4a.

Figura 4.

Fuente: Capturas proporciondas para esta investigación.

6 Los cuatro pantallazos son tomados desde el celular del sujeto con características fenotípicas femeninas, es decir, que los mensajes con fondo verde (los enviados) son referentes al personaje 2 y los de fondo blanco (los recibidos) corresponden al personaje 1 . 
En las relaciones de pareja prima la necesidad de entender (ver) al otro como objeto de valor, en tanto, esa otredad está dotada de una carga axiológica instaurada de manera mutua. En el caso puntual, son desconocidas las intenciones adicionales de los personajes dentro de la conversación, más específicamente en el personaje 2, debido a la postura de disgusto que presenta desde que inicia la interacción. Es muy usual que en este tipo de situaciones, se recurra a dejar hilos abiertos de posibilidades interpretativas en donde el propósito es esconder lo que realmente se desea expresar, para que sea el otro quien descubra las intenciones verídicas detrás del mensaje. Aquí se hace manifiesto un deseo de imposición de una conversación para ser leída "entre líneas" (Figura 5). Al respecto, investigaciones precedentes como la de Hertlein y Blumer (2014) confirman que "las conductas ambiguas y engañosas son más comunes y aceptables que las conductas explícitas" (citado por González-Rivera, 2019, p. 45).

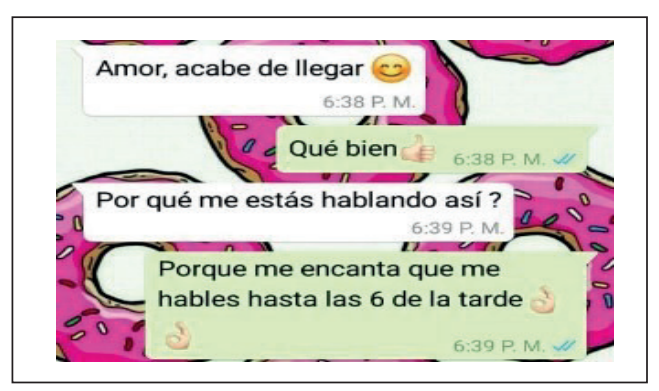

Figura 5.

Fuente: Capturas proporciondas para esta investigación.

Por otro lado, ese actuar manifiesto va ligado a la dependencia que genera el uso de la app con relación a un ideal establecido por convención social que determina la necesidad de estar en contacto permanente a través Whatsapp con la pareja sentimental a lo largo del día $y$, con base en esto, evidenciar el "amor" que siente uno por el otro. Así lo señala Enrique García Huete (s.f.):

Este es un canal perfecto para reforzar las relaciones en la primera fase de enamoramiento, pero que después puede acarrear problemas si uno de los cónyuges se obsesiona por estar en permanente contacto con su pareja o en controlar cuándo se conecta o desconecta (citado por Ricou, 2012, párr. 2).

Contingencia que precisaría la posible razón en el comportamiento en el personaje 2. Ahora bien, los individuos se ven inmersos en un sincretismo actancial ya que se le adjudican los tres roles principales que ocupan los sujetos en la narración (Greimas, 1976) Ambos personajes desempeñan el rol de sujeto, antisujeto y judicador. Tal relación permite desmenuzar las condiciones sometidas a la correlación dicotómica que llevan los actantes en la narración.

Para ejemplificar, es pertinente esclarecer que los sujetos siempre han de requerir necesariamente de unas condiciones que lo motivan a actuar. En el caso del personaje 1, manifiesta su intención por cambiar y entender el estado emocional que presenta el personaje 2; de igual forma, evalúa el contenido de los mensajes que él mismo está empleando con la finalidad de cambiar el sentido de la conversación y direccionarla según sus intereses, pero también se concreta como antisujeto para el personaje 2 por no abordar la situación y expresarse de acuerdo con los intereses de ésta (Figura 6 y $6 a)$. 


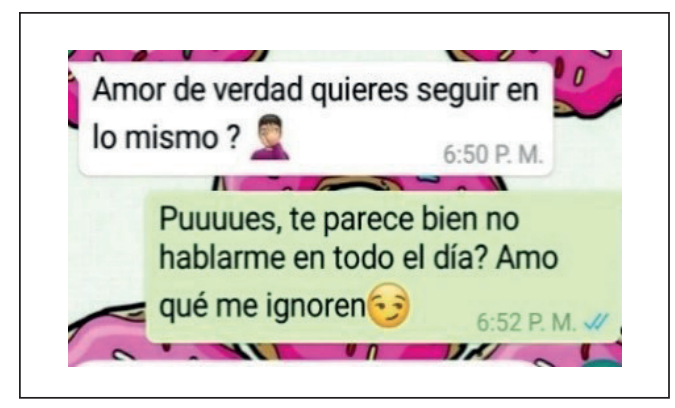

Figura 6.

Fuente: Capturas proporciondas para esta investigación.

Del mismo modo, el personaje 2 expresa notoriamente la necesidad de persuadir al personaje 1 haciendo uso de ironías, como se mencionó anteriormente, y evaluando su accionar como estrategia de manipulación a la hora de obtener la

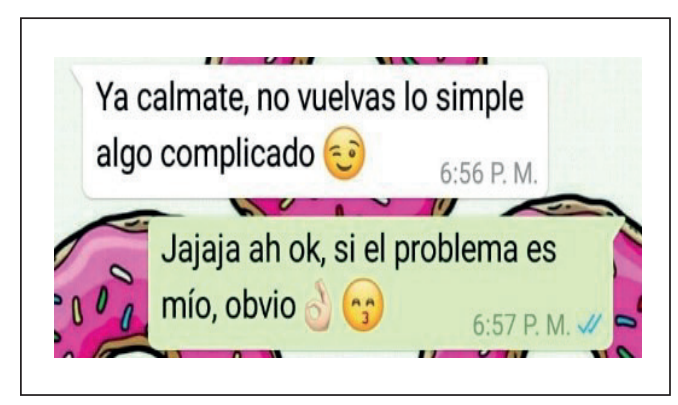

Figura 7.

Fuente: Capturas proporciondas para esta investigación.

En consecuencia, el accionar humano va ligado a los procesos de manipulación con el fin de persuadir el estado y el comportamiento de los sujetos. Entre las tipologías que plantea Greimas (1976) para la manipulación sobresale la provocación a la hora de tergiversar el significado, en este caso, conferido a cada emoji como herramienta para poner en duda las competencias del otro. El personaje 2 hace uso de modalizadores actualizantes tales como: el saber y poder en su pretensión de manipular al

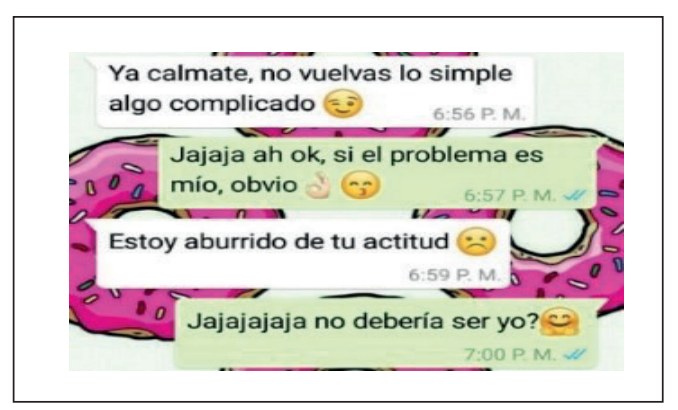

Figura 6a.

razón en medio del conflicto. Actúa, además, como antisujeto del personaje 1 por representar el obstáculo para que la interlocución se desarrolle de acuerdo a su deseo de transformar la discusión en una conversación amena (Figura 7 y 7a).

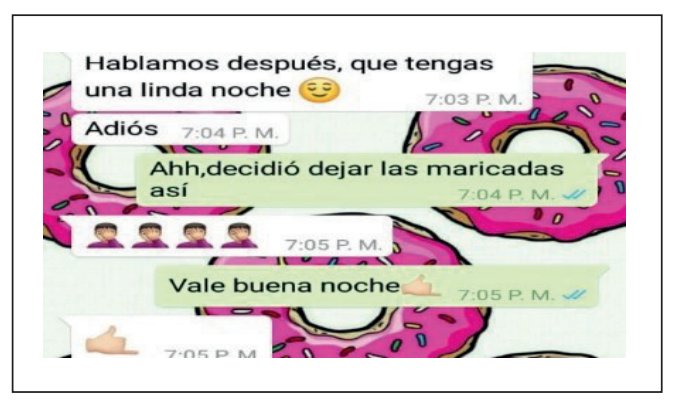

Figura $7 a$.

sujeto 1 , e igualmente como mecanismo de defensa en medio del conflicto. Al respecto se refiere que:

Puede ejercer su hacer persuasivo apoyándose sobre la modalidad del poder (...) propondrá entonces al manipulado, objetos positivos (valores culturales) o negativos (amenazas); en otros casos, persuadirá al destinatario mediante el saber (...) le hará entonces saber lo que él piensa de 
su competencia modal en forma de juicios positivos o negativos (Greimas \& Courtés, 1982, p. 252).

Se hace énfasis en grafemas acompañados de los siguientes emoticones: las caritas felices o sonrientes, la carita feliz al revés, la mano con la expresión del pulgar hacia arriba, representado la expresión okey, la mano aplaudiendo y la carita guiñando un ojo.

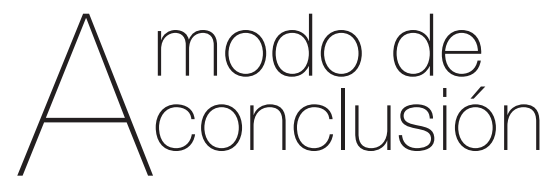

Los contenidos sígnicos del objeto de análisis giran en torno a emociones afectivas permeadas por combinaciones de sentimientos y sensaciones que se valoran como hilo conductor de la acción en pareja, y la relevancia de definir como ésta va relacionada directamente a la cognición del ser, es decir, la dicotomía entre cuerpo y alma, factor responsable de tomar las decisiones según las circunstancias en el momento de la interacción tanto física como virtual.

Por consiguiente, a pesar de que los sujetos son conscientes de que el amar va más allá del simple estado anímico vinculado a la felicidad y la estabilidad, éste puede conllevar al desarrollo de una condición afectiva desbordada, en la que la pasión prima sobre la racionalidad de un individuo, en palabras de Greimas y Fontanille (2002), "la pasión aparece al descubierto como la negación de lo racional y de lo cognoscitivo, y el "sentir" desborda al percibir" (p.18).

Es por esto que las competencias se ligan a la necesidad de manipular al otro con la intención de satisfacer sus intereses personales y, en consecuencia, la situación comunicativa se torna abrumadora. Se provocan, entonces, sentimientos opuestos que se intensifican con el uso de ironías, sátiras u otras figuras literarias para modificar el significado verídico del concepto de cada palabra. En ese sentido, se hace necesaria la prevención de estas conductas agresivas en los adolescentes que, en palabras de Celis y Rojas (2015) "pueden favorecer su aceptación, tolerancia, valoración errónea y posterior permanencia en esta u otras relaciones de pareja" (p. 100).

Además, estas emociones se ven reflejadas en valores estéticos (a partir del componente visual de los emoticones), ya que resultan llamativos gracias a la percepción que efectúa el intérprete por medio de los sentidos, y éticos, referidos a establecer el cómo vivir o formar parte de una sociedad con respecto a la comunicación que se emplea en las relaciones amorosas de los jóvenes hoy en día mediante el excesivo uso de la aplicación de WhatsApp.

Finalmente, el objeto se liga a unas condiciones socioculturales vinculadas a la implementación de las aplicaciones de mensajería instantánea que promueven una interacción online a través de la cual se reflejan pensamientos y sentimientos sin necesidad del contacto físico para relacionarse entre sí gracias a la facilidad que ofrecen las apps, dejando 
de lado las opciones más rudimentarias para expresar ese amor que define realmente a una relación sentimental, predominando en esos cambios trascendentes en las formas de sentir en esta nueva era permeados por la atracción que generan las imágenes visuales y la idea de mantener el contacto constante con la pareja a pesar de la distancia. Pero más allá de las aplicaciones, el inmediatismo del smartphone y la adicción que éste genera reduce las posibilidades de imaginación y experiencias personales necesarias para la construcción de las bases sociales establecidas en una comunidad.

Las representaciones del sentir van sujetas a esa arbitrariedad del ser humano con relación a la lectura de una imagen visual como los emoticones, debido a su idea de relacionarse entre sí bajo significados aprendidos desde la infancia que instintivamente se manifiestan por medio de su emotividad, pero, de una u otra forma, se replantean conforme lo decreta la humanidad con el pasar de los años. Para ilustrar lo mencionado anteriormente se reconoce la implementación de un nuevo código no verbal (emoticones) que va adjudicado a unos parámetros impuestos por la casa creadora, teniendo como objetivo representar un concepto universal para todos a pesar de la diversificación en el sentir y pensar de cada persona. Pero la dualidad en la que se divide el ser entre el vivir de lo asimilado y modificar ese aprendizaje, según los conceptos variantes que instaura continuamente la sociedad, converge en lo que ahora son las relaciones sociales de los jóvenes en todos los ámbitos, pero mayormente en el plexo y heterogéneo ámbito amoroso.

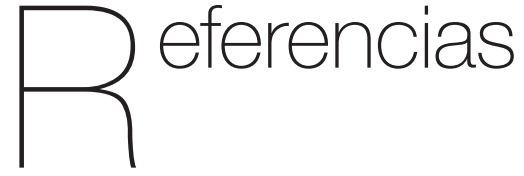

Bauman, Z. (2005). Amor líquido. Acerca de la fragilidad de los vínculos humanos. México, D.F: Fondo de Cultura Económica.

Botero, A. J. (2016). El amor en los jóvenes. Recuperado de http:// subjetividadyexpresiondepensamiento. blogspot.com/2016/10/el-amor-en-losjovenes.html

Calero, M. L. (2014). El discurso de WhatsApp: Entre el Messenger y el SMS. Oralia: Análisis del discurso oral, 1(17), 85-114. Recuperado de https://dialnet.unirioja.es/ servlet/articulo?codigo $=4860683$

Celis, A., \& Rojas, J. (2015). Violencia en el noviazgo desde la perspectiva de varones adolescentes. Informes Psicológicos, 15(1), 83-104. http://dx.doi.org/10.18566/ infpsicv15n1a05

Dutour, P. (2016). El lenguaje universal de los emojis. Cromo El Observador. Recuperado de https://www.elobservador.com. uy/nota/el-lenguaje-universal-de-losemojis-201672500

Heller, E. (2004). Psicología del Color. Barcelona: Gráficas Gustavo Gili.

Ekman, P. (1972). Universals and Cultural Differences in Facial Expressions of Emotions. Nebraska Symposium on Motivation, 19(1), 207-282. Recuperado de https://www.paulekman.com/wp-content/ uploads/2013/07/Universals-And-CulturalDifferences-In-Facial-Expressions-Of.pdf 
Ekman P. \& Harrieh O. (1979). Expresiones faciales de la emoción. Estudios de Psicología, 7(30), 527-554. Recuperado de https://dialnet.unirioja.es/servlet/ articulo?codigo $=65835$

Finol, J. E. (2015). La corposfera. Antroposemiótica de las cartografías del cuerpo. Ecuador: CIESPAL.

Fuentemayor, V. (2007). La revolución del lenguaje a través del Emoji. El heraldo. Recuperado de https://www.elheraldo. co/ciencia-y-tecnologia/la-revolucion-dellenguaje-traves-del-emoji-376135

Fontanille J. (2001). Semiótica del discurso. Lima: Fondo de Cultura Económica.

Flora, D. (2010). La comunicación no verbal. Madrid: Alianza Editorial.

Giraldo-Hurtado, C.M. \& RodríguezBustamante, A. (2018). La comunicación en las relaciones de pareja mediadas por la virtualidad en tiempos de modernidad liquida. líquida. Revista Latinoamericana de Estudios de Familia, 10(1), 11-30. Doi: 10.17151/rlef.2018.10.1.2

González-Rivera, J. A. (2019). Conductas relacionadas a la infidelidad en las Redes Sociales: validación y estudio psicométrico, Informes Psicológicos, 19(2), 43-51. http:// dx.doi.org/10.18566/infpsic. v19n2a03

Greimas A. (1976). Experiencias y proyectos. En J. Courtés (ed.) Introduction à la sémiotique narrative et discursive (pp. 5-25.) Paris: Hachette.

Greimas, A. \& Courtés, J. (1982). Diccionario razonado de la teoría del lenguaje. Madrid: Editorial Gredos.
Greimas, A. \& Fontanille J. (2002). Semiótica de las pasiones. De los estados de las cosas a los estados de ánimo. Buenos Aires: Editorial Siglo XXI.

Groupe $\mu$. (1993). Tratado del Signo Visual. Para una retórica de la imagen. Madrid: Ediciones Cátedra.

Hertlein, K. M., \& Blumer, L. C. (2014). The couple and family technology framework: Intimate relationships in a digital age. New York, NY: Routledge.

Montes, M. (2015). Hacia una semiótica de las emociones como efecto de sentido. En VI Jornadas "Peirce en Argentina. Argentina: Universidad Nacional de Córdoba.

Mubarak, I. (2014). Clasificación Fitzpatrick. Moorspanails. Recuperado de https:// www.moorspanails.com/blog/ clasificacion-fitzpatrick

Navarrete, J. (2013). ¿Qué significa realmente el doble check de Whatsapp? 24 horas. Recuperado de https://www.24horas. $\mathrm{cl} /$ tendencias/ciencia-tecnologia/quesignifica-realmente-el-doble-check-dewhatsapp-884318

Organista-Sandoval, J., McAnally-Salas, L., \& Lavigne, G. (2013). El teléfono inteligente (smartphone) como herramienta pedagógica. Apertura, 5(1), 6-19. Recuperado de https://www.redalyc.org/ pdf/688/68830443002.pdf

Peirce, C. S. (1931/1958). Collected Papers. Massachusetts: Harvard University Press.

Piergiorgio, S. (2014). El amor en los tiempos de Whatsapp. La vanguardia. Recuperado de https://www.lavanguardia.com/ 
estilos-de-vida/20141205/54420494708/ el-amor-en-los-tiempos-de-whatsapp.html

Ramos, O. (2016). La pérdida del discurso amoroso en las nuevas tecnologías. Estudio de caso de la escuela nacional preparatoria y del colegio de ciencias y humanidades de la universidad nacional autónoma de México. Escribir para el objeto amado en las nuevas tecnologías, Razón y Palabra, 84(1), 2-26. Recuperado de https://www. redalyc.org/pdf/1995/199528904039.pdf

Restrepo, M. (1993). Ser-signo-interpretante. Santafé de Bogotá: Significantes de papel Ediciones.

Ricou, J. (2012). ¿Cómo afecta el WhatsApp a las relaciones de pareja? La vanguardia. Recuperado de https://www.lavanguardia. com/vida/20121104/54354818574/ whatsapp-relaciones-pareja.html
Ruiz, S. (2005). Selección de textos de Charles S. Pierce. Buenos Aires: Mimeo.

Rodríguez, T. \& Rodríguez, Z. (2016). El amor y las nuevas tecnologías: experiencias de comunicación y conflicto, Nueva Época, 25(1), 15-41. Recuperado de http://www. scielo.org.mx/pdf/comso/n25/n25a2.pdf

Rubio-Romero, J. \& Perlado, M. (2015). fenómeno WhatsApp en el contexto de la comunicación personal: una aproximación a través de los jóvenes universitarios, Icono 14(13), 73-94. Recuperado de https:// icono14.net/ojs/index.php/icono14/article/ view/818

Savan, D. (1991). La teoria semiotica dell'emozione secondo Peirce. En Pezzini, Semiótica delle passioni (ed 1). (pp. 139157). Bologna: Esculapio. 